\title{
Giant Cell Tumor of Talus: A case report of late presentation with extensive involvement
}

\author{
by Mohan Kumar J., ${ }^{1} 凹$, Narayan Gowda ${ }^{2}$
}

The Foot and Ankle Online Journal 4 (1): 1

Giant cell tumor (GCT) of bone, or osteoclastoma, is classically described as a locally invasive tumor that occurs close to the joint of a mature bone. It is generally considered to be a benign tumor. In our rural setup, a substantial proportion of patients seek traditional means of treatment before medical consultation. A case of GCT in a 20 year-old boy which had led to extensive destruction of the talus is reported. In view of the extensive involvement, total talectomy along with tibio - calcaneal arthrodesis was performed. At 6 months of follow-up, the patient had a painless and well arthrodesed ankle. There was no evidence of recurrence at 18 months of follow-up.

Key words: GCT, osteoclastoma of the talus ,tibiocalcaneal ,arthrodesis.

Accepted: December, 2010

Published: January, 2011

This is an Open Access article distributed under the terms of the Creative Commons Attribution License. It permits unrestricted use, distribution, and reproduction in any medium, provided the original work is properly cited. (OThe Foot and Ankle Online Journal (www.faoj.org)

In the talus, giant cell tumor (GCT) of bone is an infrequent primary bone tumor that can presents late with extensive involvement of soft tissue and articular surface changes often making the joint preservation difficult or impossible. ${ }^{1}$ GCT account for approximately $5-8 \%$ of all primary bone tumors. ${ }^{2,3,4}$ The authors report a GCT which had led to destruction of the entire talus in a 20 year-old boy. In view of the extensive involvement, total talectomy along with tibiocalcaneal arthrodesis was performed with the aim of achieving a stiff but painless joint.

Address correspondence to: Department of Orthopaedics PESIMSR. Kuppam AP India 517425

1 Assistant professor, Dept of Orthopaedics PESIMSR.

${ }^{2}$ Assistant professor, Dept of Orthopaedics PESIMSR.

\section{Case presentation}

A 20 year-old boy presented with chief complaints of insidious onset pain in the left ankle since the last two years, swelling in the left ankle since the last six months and inability to bear weight on right side since the last six months. The patient was treated elsewhere with intralesional steroid. There was no history of fever, loss of appetite, loss of weight, similar complaints in other joints or history of similar complaints in the past. The family, occupational, recreational and drug histories were not significant. The general physical and systemic examinations were within normal limits. On local examination, the attitude of the limb was neutral. There was a $5 \times 4 \mathrm{~cm}$ swelling over medial and anterior aspect of left ankle joint. (Fig. 1) 


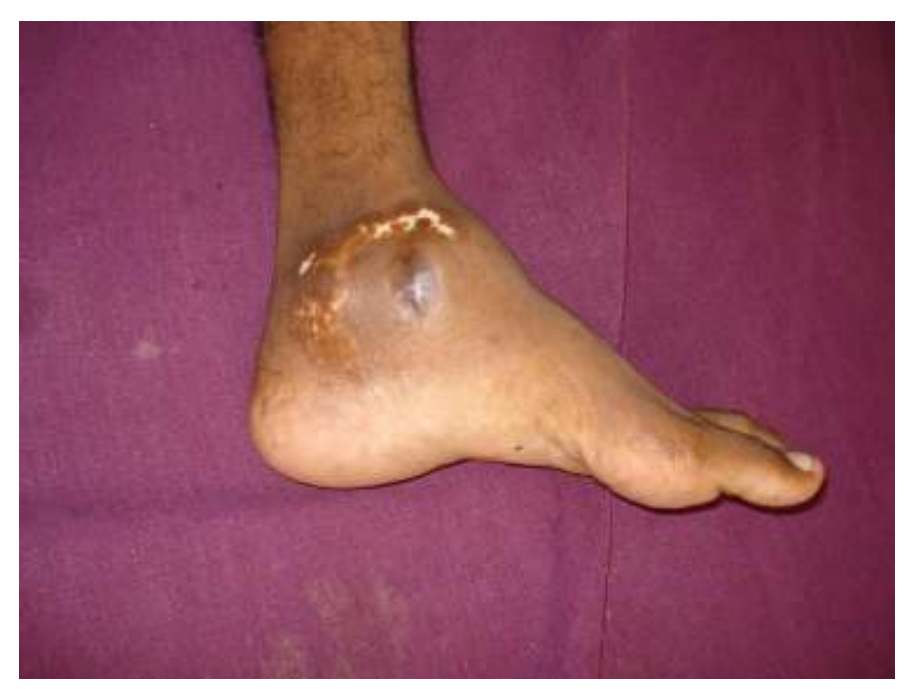

Figure 1 Clinical photo of the left ankle.

There were no visible veins, sinus or discharge from the swelling. There was hypopigmentation and the swelling was tender. All movements at the ankle joint were painfully restricted. Serum biochemistry studies were within normal limits. Anterior posterior (AP) and lateral radiographs of the ankle showed a radiolucent lesion occupying the whole talus. (Fig. 2) The magnetic resonance scan (MRI) revealed an expansible soft tissue mass in the talus causing cortical destruction and extension into soft tissues. (Fig. 3) A fine needle aspiration of the mass was performed and a provisional diagnosis of GCT was rendered.

The condition, its prognosis and various treatment modalities were discussed with the patient and his family. Because of extensive involvement of talus, total talectomy with tibiocalcaneal arthrodesis was planned. The patient was a manual labourer and therefore opted for a stiff but painless joint. Total talectomy was performed through an anterolateral approach. (Fig. 4) Fusion was achieved by autologous iliac crest graft and stabilization with a Steinmann pin and Chamley's clamp. (Fig. 5) The patient was advised non weight bearing on the affected limb for 8 weeks and mobilized in a short leg walking cast thereafter.

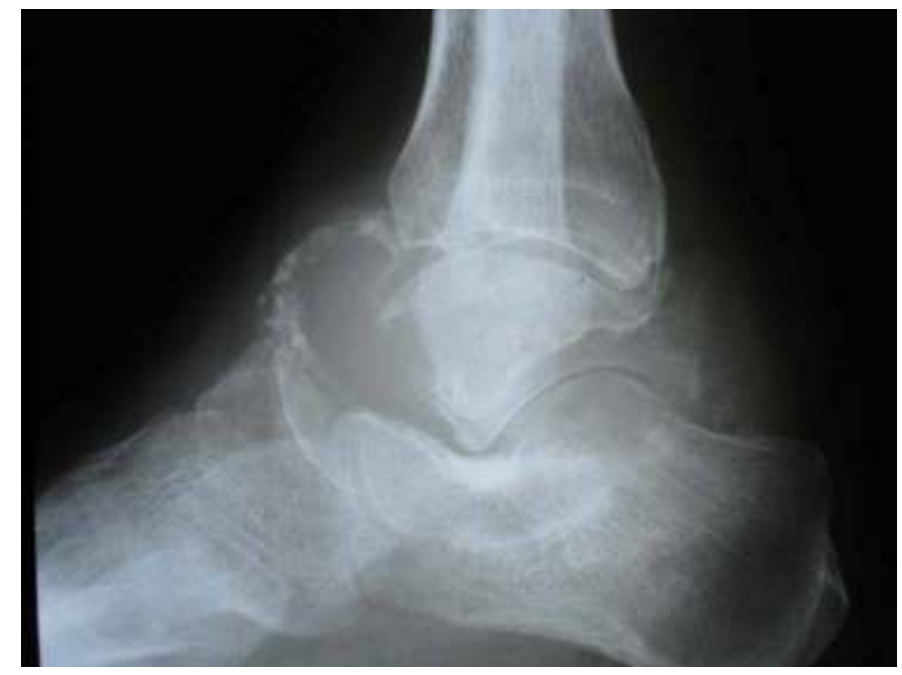

Figure2 Radiograph showing the lesion (left ankle).

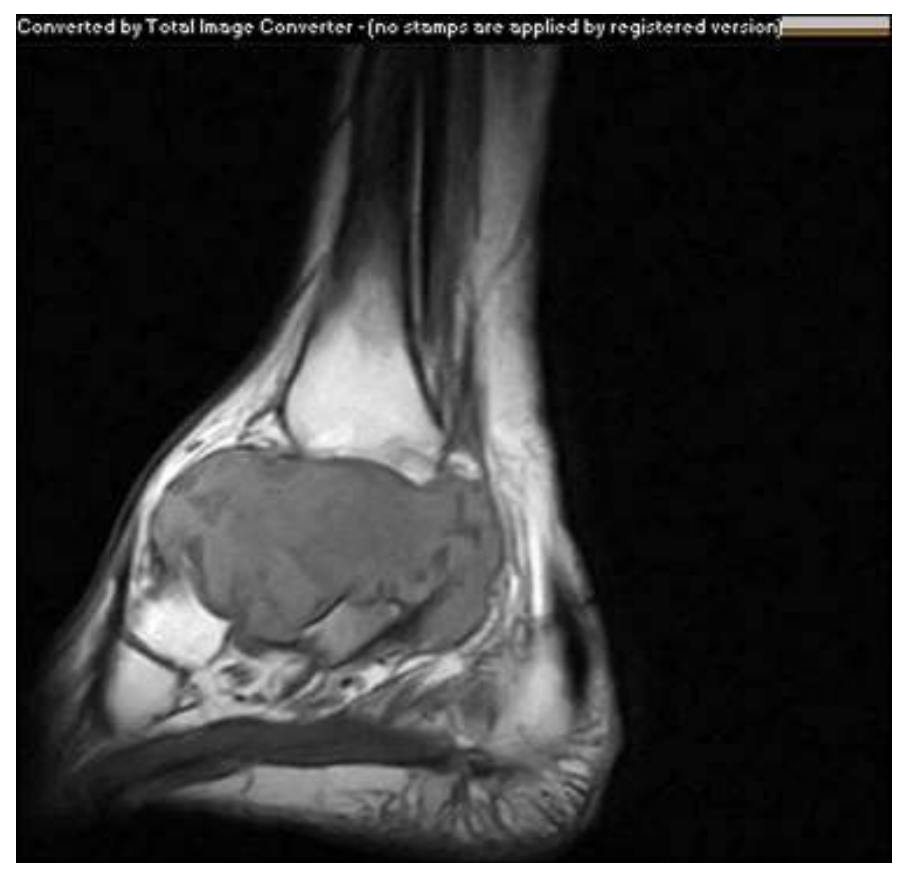

Figure 3 Preoperative MRI showing GCT extensive involvement of the left ankle.

At 6 months of follow-up (Fig. 6), the patient had a smooth healed scar with a painless and well arthrodesed ankle and no evidence of recurrence. He had shortening of $2 \mathrm{cms}$ which he managed with a shoe rise. There was no evidence of recurrence at 18 months of follow-up. 


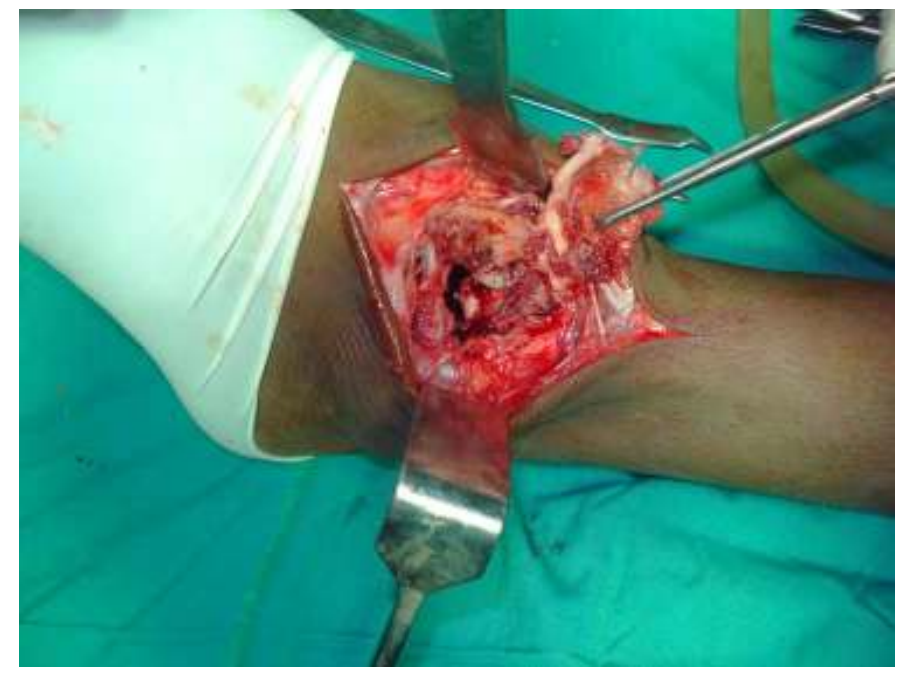

Figure 4 Intraoperative image showing the lesion.

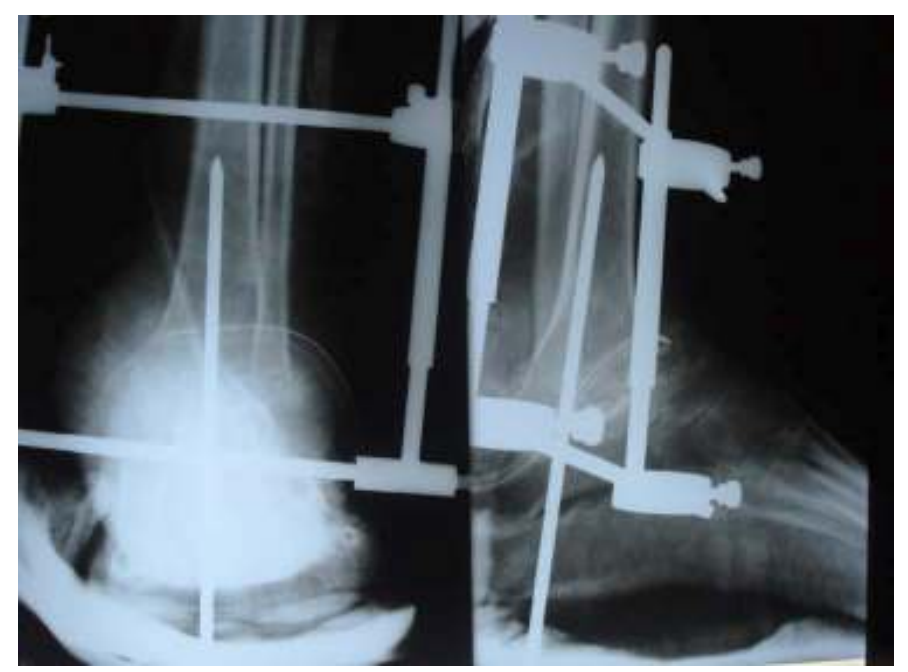

Figure 5 Immediate post-operative radiograph showing complete talectomy and pan talar fusion using external fixator.

\section{Discussion}

GCT, also known as osteoclastoma, is a fairly common bone tumor accounting for 5\% of all the primary bone tumors. It is a benign tumor with a tendency for local aggressiveness and high chances of recurrence. GCT is most commonly seen in the distal femur proximal tibia, distal radius and the proximal humerus in descending order of frequency. ${ }^{5}$

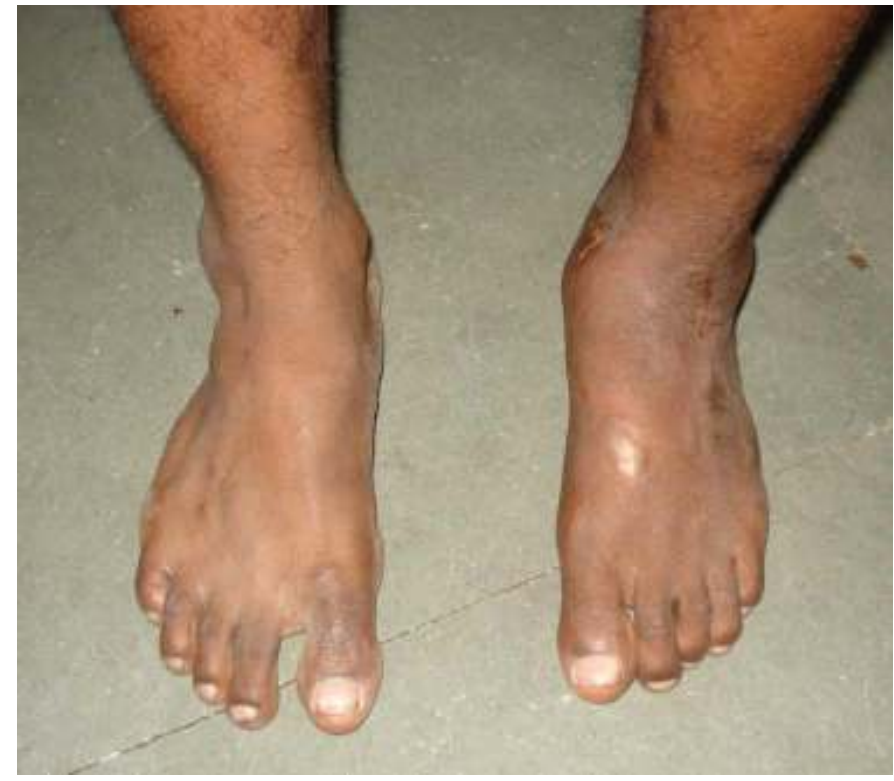

Figure 6 Clinical photo 6 months after surgery.

The foot is an unusual site of presentation and GCTs involving hand and foot bones appear to occur in a younger age group and tend to be multicentric. ${ }^{6}$ The clinical picture is that of insidious onset pain, which in many cases may be mismanaged as ankle sprain. A history of preceding trivial trauma may be present. Other features are non specific. Radiologically; the tumor appears as an eccentric lytic lesion with cortical thinning and expansion. There is absence of reactive new bone formation. The tumor may erode the cortex and invade the joint. Pathological fracture may also be seen. ${ }^{7} \quad$ MRI scanning permits accurate delineation of the tumor extent and helps in deciding the line of management i.e. (curettage versus talectomy).

Many authors have reported satisfactory results with intralesional curettage and bone grafting. ${ }^{8}$ However, curettage alone has a high rate of recurrence and adjuvants like Methylmethacrylate (bone cement), cryotherapy and phenol have been suggested.

Partial or total talectomy may be contemplated in cases where there is extensive involvement of the talus. Arthrodesis may or may not be done, but it is said that arthrodesis is essential after resection of all tarsal bones except calcaneum. 
Fresh frozen osteochondral allograft reconstruction has also been described for an aggressive GCT of talus but there is paucity of literature on this particular modality of treatment. ${ }^{10}$ The trend is towards limb salvage and amputation is reserved for recurrences and only rarely done. In conclusion, in a case of GCT of talus presenting late with extensive involvement and in a manual labourer, total excision and tibiocalcaneal arthrodesis is an valuable treatment option.

\section{References}

1. Ng ES, Saw A, Sengupta S. Giant cell tumour of bone with late presentation: review of treatment and outcome Journal of Orthopaedic Surgery 2002: 10(2): 120-128.

2. Huvos AG Bone Tumours: Diagnosis, Treatment and Prognosis. 1979, $1^{\text {st }}$ Edition, Saunders, Philadelphia p265.

3. Schajowicz F. Tumors and Tumor Like Lesions of Bone and Joints. New York, NY: Springer; 1981.p 205.

4. Dahlin DC. Bone Tumours: General Aspects and Data on 6221 cases. 1981, $3^{\text {rd }}$ Edition. Charles C Thomas Publisher, Springfield p99.

5. Stoker DJ. Bone tumors (1): general characteristics benign lesions. In: Grainger RG, Allison DJ (Editors). Diagnostic radiology a textbook of medical imaging. $3^{\text {rd }}$ Edition. New York: Churchill Livingston; 1997. p. 629-1660,

6. Wold LE, Swee RG. Giant cell tumor of the small bones of the hand and feet. Semin Diagn Pathol 1984, 1:173-184.

7. Carrasco CH, Murray JA. Giant cell tumours. Orthop Clin North Am 1989, 20: 395- 405.

8. Bapat MR, Narlawar RS, Pimple MK, Bhosale PB. Giant cell tumour of talar body. J Postgrad Med 2000, 46:110.

9. Dhillon MS, Singh B, Gill SS, Walker R, Nagi ON.

Management of giant cell tumor of the tarsal bones: a report of nine cases and a review of the literature. Foot Ankle 1993, 14(5):265-272.

10. Schoenfeld AJ, Leeson MC, Grossman JP. Fresh-frozen osteochondral allograft reconstruction of a giant cell tumor of the talus. J Foot Ankle Surg 2007, 46(3):144-148. 